\section{Dr. Ricardo Cruz-Coke Madrid, Editor Asociado de la Revista Médica de Chile}

\section{Ricardo Cruz-Coke, MD, former Associate Editor, Revista Médica de Chile}

El doctor Ricardo Cruz-Coke Madrid nació en Santiago el 13 de agosto de 1925 y falleció el 26 de octubre de 2016. En 1950 obtuvo el título de Médico Cirujano, en la Universidad de Chile. Continuó con estudios de postgrado en la Universidad de París, en el Hospital Broussais (1954) y en el Hospital Necker (1957) complementándolos en la década de 1960 en el Hospital Johns Hopkins de Baltimore, el principal centro de genética médica en Norteamérica. Durante toda su carrera se comprometió con dedicación exclusiva a la actividad universitaria, alcanzando la jerarquía de Profesor Titular de la Universidad de Chile. Fue fundador y jefe de la Sección Genética del Hospital José Joaquín Aguirre. Fue uno de los más destacados investigadores y docentes en genética médica y de poblaciones humanas, impulsó el uso de la computación en medicina y tuvo reconocimiento internacional por sus estudios sobre la relación entre factores genéticos e hipertensión arterial, originando numerosas publicaciones en las principales revistas científicas nacionales e internacionales. Participó en 80 congresos científicos, en 40 países. Además, sus conocimientos de ciencia política y de matemática lo llevaron a ser consultado como experto por el antiguo servicio electoral, llegando a publicar libros como "Geografía electoral de Chile" (1952) e "Historia electoral de Chile" (1984). Otro aspecto de su amplitud cultural se refleja en sus libros "El hombre y su planeta" (1962), "Color Blindness" (1970), "Historia de la Medicina Chilena" (1995, calificada como una publicación clásica en esta materia), "Genética Social" (1999). Entre 1957 y 1995 fue Editor Asociado de la Revista Médica de Chile, contribuyendo en funciones similares en las revistas Clinical Genetics y Vida Médica. Entre 1957 y 1998 fue miembro del Consejo Superior de Educación. Fue presidente de la Sociedad Chilena de Genética y de la Asociación Latinoamericana de Genética, fundador y presidente del Programa

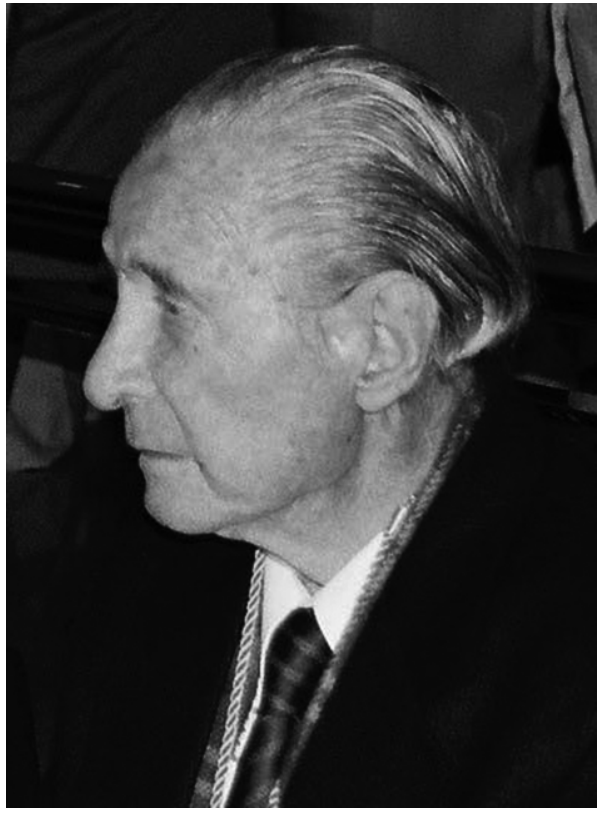

Latinoamericano del Genoma Humano, miembro del Comité de Expertos de la Organización Mundial de la Salud y de la Comisión de Bioética de la UNESCO. Recibió importantes distinciones académicas de diversos países americanos y europeos, y la Medalla Rector Juvenal Hernández Jaque, otorgada por la Universidad de Chile (2003). Destacó por su interés y sapiencia en distintas áreas de las humanidades médicas, particularmente en historia de la medicina y en ética médica. Su última empresa, con noventa años de edad, fue un intento épico de resumir la Historia de la Medicina en la Universidad de Chile, en un opúsculo que obsequió a sus colegas en la Academia Chilena de Medicina, donde fue Miembro de Número desde 1985. Al recuerdo de su vida profesional debemos agregar sus cualidades humanas: su rectitud, honestidad, firmeza en la defensa de sus principios morales y de su fe, y la calidez de su amistad.

Dr. Humberto Reyes B.

Presidente de la Academia Chilena de Medicina Editor Emérito de la Revista Médica de Chile 